\title{
Diagnostic delay in axial spondyloarthritis: a systematic review
}

\author{
Charles A. Hay ${ }^{1}$ D . Jon Packham ${ }^{1,2,3} \mathbb{D} \cdot$ Sarah Ryan $^{3,4} \mathbb{D} \cdot$ Christian D. Mallen $^{1,3}\left(\mathbb{D} \cdot\right.$ Alexandros Chatzixenitidis $^{1} \mathbb{D}$. \\ James A. Prior ${ }^{1,3}$
}

Received: 18 October 2021 / Revised: 1 February 2022 / Accepted: 13 February 2022 / Published online: 19 February 2022

(c) The Author(s) 2022

\begin{abstract}
Identification of axial spondyloarthritis (axSpA) remains challenging, frequently resulting in a diagnostic delay for patients. Current benchmarks of delay are usually reported as mean data, which are typically skewed and therefore may be overestimating delay. Our aim was to determine the extent of median delay patients' experience in receiving a diagnosis of axSpA and examine whether specific factors are associated with the presence of such delay. We conducted a systematic review across five literature databases (from inception to November 2021), with studies reporting the average time period of diagnostic delay in patients with axSpA being included. Any additional information examining associations between specific factors and delay were also extracted. A narrative synthesis was used to report the median range of diagnostic delay experienced by patients with axSpA and summarise which factors have a role in the delay. From an initial 11,995 articles, 69 reported an average time period of diagnostic delay, with 25 of these providing a median delay from symptom onset to diagnosis. Across these studies, delay ranged from 0.67 to 8 years, with over three-quarters reporting a median of between 2 years and 6 years. A third of all studies reported median delay data ranging from just 2 to 2.3 years. Of seven variables reported with sufficient frequency to evaluate, only 'gender' and 'family history of axSpA' had sufficient concordant data to draw any conclusion on their role, neither influenced the extent of the delay. Despite improvements in recent decades, patients with axSpA frequently experience years of diagnostic delay and this remains an extensive worldwide problem. This is further compounded by a mixed picture of the disease, patient and healthcare-related factors influencing delay.
\end{abstract}

\section{Key points}

- Despite improvements in recent decades, patients with axSpA frequently experience years of diagnostic delay.

- Median diagnostic delay typically ranges from 2 to 6 years globally.

- Neither 'gender' nor 'family history of axSpA' influenced the extent of diagnostic delay experienced.

- Diagnostic delay based on mean, rather than median, data influences the interpretation of the delay time period and consistently reports a longer delay period.

Keywords Ankylosing spondylitis · Axial spondyloarthritis · Diagnostic delay

\author{
James A. Prior \\ j.a.prior@keele.ac.uk \\ Charles A. Hay \\ c.hay@keele.ac.uk \\ Jon Packham \\ jon.packham@mpft.nhs.uk \\ Sarah Ryan \\ sarah.ryan2@mpft.nhs.uk \\ Christian D. Mallen \\ c.d.mallen@keele.ac.uk
}

\author{
Alexandros Chatzixenitidis \\ a.chatzixenitidis@keele.ac.uk \\ 1 School of Medicine, Keele University, Keele ST5 5BG, UK \\ 2 Academic Unit of Population and Lifespan Sciences, \\ University of Nottingham, Nottingham, UK \\ 3 Midlands Partnership NHS Foundation Trust, Stafford, UK \\ 4 School of Nursing and Midwifery, Keele University, \\ Keele ST5 5BG, UK
}




\section{Introduction}

Axial spondyloarthritis (axSpA) is inflammatory arthritis characterised by inflammation in the sacroiliac joints (SIJ) and the axial spine, with symptoms such as chronic back pain, stiffness and fatigue most commonly manifesting in early adulthood [1]. In a 2017 UK representative primary care population, the incidence of axSpA was found to be 8.0 per 100,000 person-years and the prevalence 15.8 per 10,000 population [2].

The diagnosis of axSpA remains challenging due to the often-insidious onset of this condition, with initial presentation not always being immediately apparent as an inflammatory disease. Furthermore, although chronic back pain (CBP) lasting longer than three months is a key characteristic of axSpA, it frequently occurs in many patients with non-inflammatory back pain [3]. Hamilton et al. estimated that the prevalence of axSpA in the UK population of adults with CBP was only $1.3 \%$ [4], suggesting the vast majority of CBP in the general population is caused by conditions other than axSpA. Unfortunately, patients with axSpA commonly experience substantial delays before receiving a definitive diagnosis [5]. Such delay in the diagnosis of axSpA presents significant, multifaceted burdens to patients and society. Previous research has found that patients with axSpA who experience diagnostic delay have poorer general and disease-specific quality of life [6,7], more progressive disease development [8], experience a reduced efficacy of disease-modifying medication [9] and report increased work disability $[10,11]$.

Despite these serious consequences, the factors associated with a delay in the diagnosis of axSpA and its true extent remain unclear. Although a recent 2021 systematic review and meta-analysis by Zhao et al. found the mean time period of delay in axSpA diagnosis to be 6.7 (6.2, 7.2) years globally and $8.6(7.3,10.0)$ years in the UK specifically, there remains a significant limitation with these estimates [12]. Diagnostic delay data is typically skewed by outliers, making the pooling of mean data less reliable and increasing the potential of an overestimation of the delay occurring in a population. The use of median data is recommended in the analysis of skewed data [5], and although this data cannot be pooled through metaanalysis to provide a convenient single average estimate of delay, a more accurate and reliable probable data range can be established. It also remains unclear whether specific patient-related factors, disease characteristics or healthcare systems processes have an influence on the extent of delay experienced by certain groups.

The aim of this systematic review was to ascertain the extent of, and potential reasons for, diagnostic delay in people with axSpA. Our two specific objectives were (1) to synthesise published literature detailing a median time period of delay from symptom onset to final diagnosis in patients with axSpA to determine a benchmark delay range and (2) to examine any factors associated with the extent of diagnostic delay experienced by patients with axSpA.

\section{Methods}

A systematic review was conducted using five medical literature databases, and articles were searched for from journal inception to November 2021. These databases were Medline, EMBASE, AMED, CINAHL and Web of Science. The protocol was registered with PROSPERO in 2018 (registration number: CRD42019118963).

\section{Study selection}

For studies to meet the inclusion criteria, several factors were required, with the primary outcome of interest, an average time period of diagnostic delay for axSpA (mean or median at inclusion stage). This also included any reporting of delay in time period subsets between symptom onset to final diagnosis (e.g., symptom onset to the first consultation, rather than the final diagnosis). Further inclusion criteria required that study types used cross-sectional, cohort, case-control or RCTs design of at least 20 adult participants. There were no restrictions on language, but those which could not be translated were not included in the systematic review. Additional to this search strategy, reference lists of existing reviews and included studies were reviewed to ensure the inclusion of any studies which may have been missed in the search strategy. Additionally, authors were contacted for any important missing data. Where further data was made available by authors, they are presented in this review as being linked with the published material.

Medical subject headings (MeSH) terms, or their database-specific equivalents, were searched, along with freetext phrases across all databases. The diagnostic/classification terminology of axial spondyloarthritis has evolved over time, and this was reflected in the search strategy created (Supplementary Table 1). Citations were exported into the reference management software Endnote X8, where duplicate articles were removed automatically. Using the specified inclusion criteria, articles were then initially screened by the first reviewer $(\mathrm{CH})$ by title only, with any further de-duplication not achieved by Endnote being undertaken at this stage. After the review by title had been completed, a second reviewer (AC) was invited for the abstract review stage and the remaining articles were exported to Rayyan QCRI (https://www.rayyan.ai/) to facilitate a blinded review process based on abstract content. Following the abstract review stage, $\mathrm{CH}$ and $\mathrm{AC}$ both reviewed the remaining articles by full text. In the case of any disagreement between 
reviewers one and two, a third reviewer (JAP) arbitrated to reach a final decision. Finally, the reference lists of included studies were searched for further relevant studies.

\section{Data extraction and quality assessment}

Data was extracted from all studies by a first reviewer $(\mathrm{CH})$, with secondary data extraction being undertaken by a second (AC) and a third reviewer (JAP), each extracting data from half the included articles. Extracted data included the primary outcome of the time period of diagnostic delay, and study setting, sample size, country of origin, gender distribution of study population, method of diagnosis and any specific factors examined in relation to the experience of diagnostic delay. Methodological quality assessment was undertaken using the Newcastle-Ottawa (N-O) scale [13], with only questions which were deemed pertinent to this review retained. Quality assessment of all included studies was conducted independently by CAH and JAP.

\section{Analysis: extent of average diagnostic delay}

A narrative synthesis was first undertaken to characterise extracted data. After extraction, for ease of comparison and interpretation across studies, reported time periods of diagnostic delay were standardised to number of years to two decimal places. Data were extracted from all studies which reported an average time period of diagnostic delay for axSpA, but for the purposes of this systematic review, those studies reporting median diagnostic delay were prioritised due to these being a potentially more accurate representation of the distribution of diagnostic delay. Finally, throughout the literature, both the terms ankylosing spondylitis and axial spondyloarthritis are used. While ankylosing spondylitis is now more commonly used as a synonym for radiographic-axSpA, it has historically been used to describe the entirety of axSpA and is still occasionally used synonymously with the entire spectrum of disease. Both terms were acceptable for inclusion, but to ascertain whether the terminology was related to trends in reported delay, a sensitivity analysis was undertaken by categorising reported delay by condition definition.

\section{Analysis: factors associated with diagnostic delay}

Analysis on the extent of total diagnostic delay focused on median data. However, we did not impose this same restriction on articles which had examined differences in delay associated with specific factors (i.e. a family history of axSpA), and as such, different comparative approaches were taken to reflect different elements of delay. Firstly, to assess how the extent of diagnostic delay has changed over time, we compared articles reporting delay across multiple time-points in the same population. Secondly, to assess the role of a specific factor on delay required the primary outcome to be the existence of a comparison between the extent of delay between samples with or without a specific factor (e.g., comparison of diagnostic delay between men and women with axSpA). Here, our focus was on the existence of an examined difference between groups, and not the extent of the delay experienced. Where a specific factor of diagnostic delay was examined in five or more articles, the outcome of any statistical tests was recorded to examine whether a factor did, or did not, have a role in influencing the diagnostic delay experienced by patients with axSpA.

\section{Results}

\section{Literature search}

An initial 11,995 articles were identified, 2581 of which were duplicates; 8358 titles were excluded based on their title, leaving 1056 abstracts for review, followed by 158 articles to be reviewed in full. Finally, upon searching the references of the remaining articles, 16 more were found to be eligible for the systematic review, bringing the total number of articles included to 69 . Of these, 59 reported either overall median diagnostic delay data or delay data related to a specific factor. This resulted in the identification of 25 individual median values which had specially examined the extent of diagnostic delay using the definition 'from symptom onset to final diagnosis' (Fig. 1). Finally, from the 34 articles which had examined the relationship between a specific factor and diagnostic delay in an axSpA sample, 4 had reported the change in delay over specific time periods.

\section{Extent of diagnostic delay}

Twenty-five studies used the same definition, reporting median delay between the initial onset of axSpA symptoms and final diagnosis for the whole sample. Four studies were from Turkey [14-17], three from China [18-20], two each from Germany [21, 22], India [23, 24], South Korea [9, 25] and the UK [5, 26], and one each from the Czech Republic [27], Denmark [28], France [29], Iran [8], Italy [30], Norway [31], Saudi Arabia [32], Spain [33] and Thailand [34]. Garrido-Cumbrera et al. (2019) reported an overall diagnostic delay for Europe, including 13 countries (Austria, Belgium, France, Germany, Italy, the Netherlands, Norway, Russia, Slovenia, Spain, Sweden, Switzerland and the UK) [35]. The point at which average age was recorded across studies was not uniform and often recorded at multiple points, including at the time of the study, symptom onset or diagnosis. However, across these studies, the 'average age at the time of the study' ranged from the youngest at 32 years [20, 24] 
Fig. 1 Flow diagram of the number of articles at each stage of the search and screening process

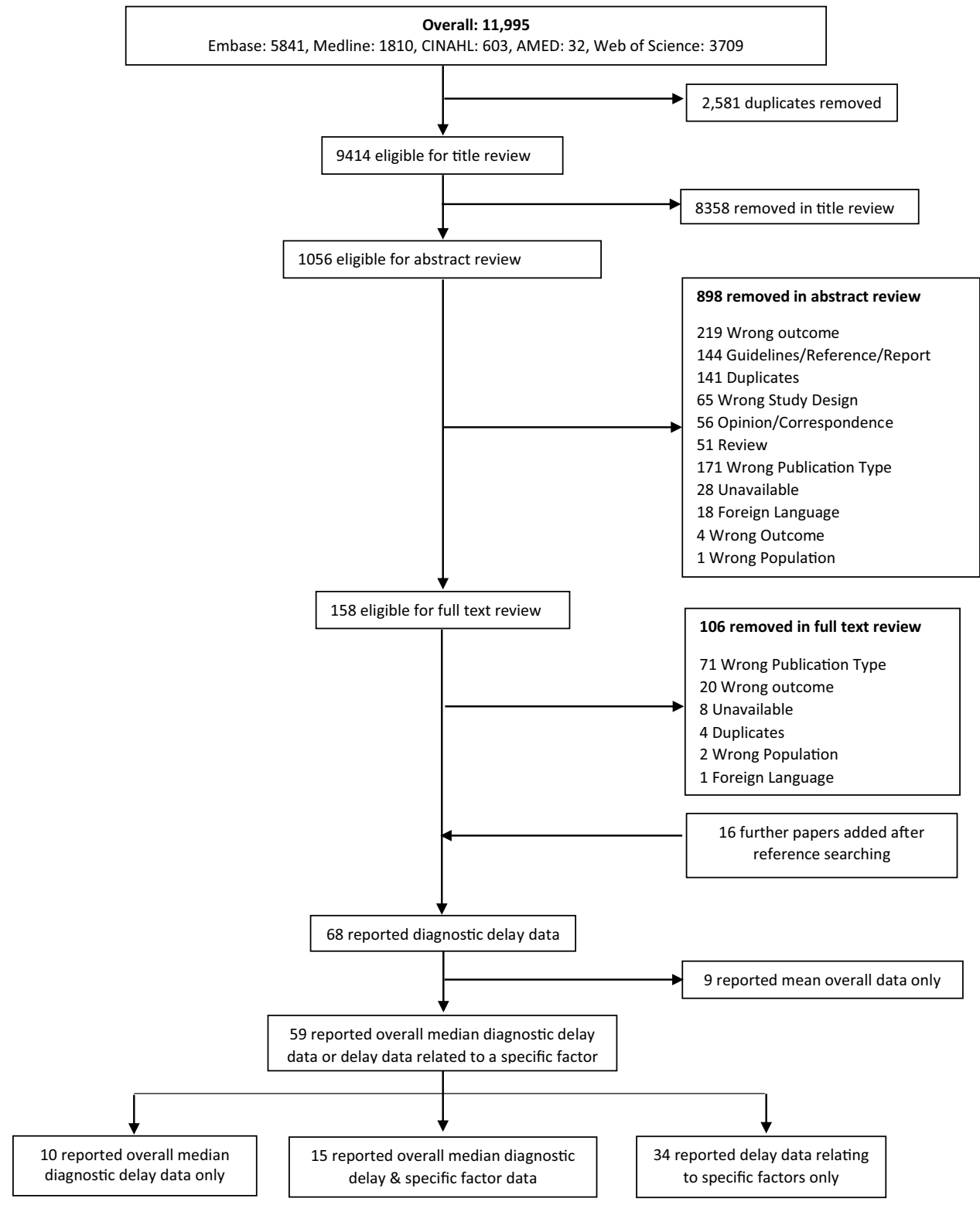

through to the oldest age of 55.9 years [22]. Where reported, males formed the majority of patients within all but one of the articles [35], with the percentage of males ranging from $52.9 \%$ [33] to $84.3 \%$ [23] (Table 1).

The disease and diagnostic definitions were not standardised throughout the literature. Fourteen of the studies examining overall diagnostic delay described their patients as being diagnosed with ankylosing spondylitis (AS) [8, 14-16, 18, 20, 23, 25-29, 31, 33]. Ten of these [8, 14-16, $18,20,23,25,27,31]$ defined AS using the modified New York Criteria (mNYC) [36], with one [29] using Assessment of Spondyloarthritis International Society (ASAS) criteria $[37,38]$. The remaining three defined AS using International Classification of Diseases (ICD) codes [28], self-report [26] or through medical record [33]. Eleven studies described their patients as having axSpA [5, 9, 17, 19, 21, 22, 24, 29, 32, 34, 35]. Six of these [9, 17, 19, 24, 29, 34] classified axSpA using the ASAS criteria, while Brandt et al. used the mNYC [21], Sykes et al. and Merino et al. relied on physician verification [5, 33], Garrido-Cumbrera et al. relied on self-report [35] and Redeker et al. used ICD 10 codes [22].

Across the 25 studies, median diagnostic delay ranged from an average of 0.67 years in Denmark [28] to 8 years in South Korea [9]. Within this data range, though the one study reported a median delay of 0.67 years, over threequarters of studies $(80 \%)$ reported delay between 2 years and 6 years, with the articles reporting 2-2.3 years making up a third of the total $(n=8)$. A final three studies reported delay of 7 or 8 years (Table 2). When sensitivity analysis was undertaken by stratifying overall time periods of diagnostic 
Table 1 Study characteristics for articles reporting median delay from symptom onset to axSpA diagnosis $(n=25)$

\begin{tabular}{|c|c|c|c|c|c|c|c|c|c|}
\hline \multirow[t]{2}{*}{ Author } & \multirow[t]{2}{*}{ Year } & \multirow[t]{2}{*}{ Country } & \multirow[t]{2}{*}{ Sample size } & \multicolumn{3}{|l|}{ Average age } & \multicolumn{2}{|l|}{ Gender } & \multirow[t]{2}{*}{ Definition } \\
\hline & & & & At time of study & At disease onset & At diagnosis & Male \% & $\mathrm{M}: \mathrm{F}$ & \\
\hline Seo et al. & 2014 & South Korea & 94 & 40 (IQR 39-49) & 23 (IQR 17-30) & 35 (IQR 24-43) & 78.7 & - & $\operatorname{axSpA}$ \\
\hline Forejtova et al. & 2008 & Czech Republic & 979 & $50.2($ SD 10.7) & $27.3(\mathrm{SD} 8.5)$ & - & 62.2 & $1.65: 1$ & AS \\
\hline Bakland et al. & 2011 & Norway & 677 & - & $23.2(\mathrm{SD} 8.5)$ & - & - & $3.1: 1$ & AS \\
\hline Fallahi et al. & 2016 & Iran & 163 & 37.7 (SD 9.9) & $23.4(\mathrm{SD} 7.1)$ & $31.3(\mathrm{SD} 9.7)$ & 79 & - & AS \\
\hline Hamilton et al. & 2011 & UK & 807 & - & - & - & - & $3: 1$ & AS \\
\hline Merino et al. & 2021 & Spain & 469 & $46.0(\mathrm{SD} 11.0)$ & $23.8(\mathrm{SD} 8.5)$ & $32.2(\mathrm{SD} 9.5)$ & 52.9 & - & $\operatorname{axSpA}$ \\
\hline Aggarwal et al. & 2009 & India & 70 & - & $23(\mathrm{SD} 8.8)$ & 31.5 (SD 8.7) & 84.3 & $5: 1$ & AS \\
\hline Brandt et al. & 2007 & Germany & 350 & 40 (range $16-75)$ & - & - & - & - & $\operatorname{axSpA}$ \\
\hline Sykes et al. & 2015 & UK & 1193 & - & - & - & - & - & $\operatorname{axSpA}$ \\
\hline Gerdan et al. & 2012 & Turkey & 393 & 39.3 (SD 10.8) & - & - & 65.6 & - & AS \\
\hline Limsakul et al. & 2021 & Thailand & 177 & 39.5 (SD 10.4) & $28.5(\mathrm{SD} 9.6)$ & 36.1 (SD 10.5) & 62.1 & - & $\operatorname{axSpA}$ \\
\hline $\begin{array}{l}\text { Garrido-Cumbrera } \\
\text { et al. }\end{array}$ & 2019 & Europe & 2846 & $43.9(\mathrm{SD} 12.3)$ & $26.2(\mathrm{SD} 11.1)$ & 33.7 (SD 11.5) & 38.6 & - & $\operatorname{axSpA}$ \\
\hline Zengin et al. & 2021 & Turkey & 308 & 36 (IQR 31-45) & - & 31 (IQR 27-40) & 58.8 & - & $\operatorname{axSpA}$ \\
\hline Ozgocmen et al. & 2009 & Turkey & 279 & $36.11(\mathrm{SD} 10.2)$ & 25.63 (SD 7.49) & 30.7 (SD 9.42) & 73 & - & AS \\
\hline Omair et al. & 2017 & Saudi Arabia & 134 & - & 26 (IQR 20-33) & $30(25-38)$ & 67.2 & - & $\operatorname{axSpA}$ \\
\hline Redeker et al. & 2019 & Germany & 4471 & 55.9 & 30.6 & - & 54.1 & - & $\operatorname{axSpA}$ \\
\hline Li et al. & 2019 & China & 208 & $35.5(\mathrm{SD} 12.8)$ & $28.1(\mathrm{SD} 12.3)$ & - & 71.6 & - & $\operatorname{axSpA}$ \\
\hline Salvadorini et al. & 2012 & Italy & 135 & - & $28.3(\mathrm{SD} 10.2)$ & $26.5(\mathrm{SD} 12.2)$ & - & $90: 45$ & $\operatorname{axSpA}$ \\
\hline Bodur et al. & 2010 & Turkey & 1381 & 39.5 (SD 10.7) & 27.5 (SD 9.8) & 32 (SD 10.7) & 75.2 & - & AS \\
\hline $\begin{array}{l}\text { Masson Behar } \\
\text { et al. }\end{array}$ & 2016 & France & 432 & - & $29.3(\mathrm{SD} 12.2)$ & $34.2(\mathrm{SD} 12.5)$ & 56.2 & - & $\mathrm{AS}$ \\
\hline Qian et al. & 2017 & China & 1251 & - & $29.2(11.4)$ & $33.5(12.6)$ & 73.2 & - & $\mathrm{AS}$ \\
\hline Reddy et al. & 2020 & India & 100 & $\begin{array}{l}32 \text { (IQR 26.0- } \\
36.7 \text { ) }\end{array}$ & - & - & 68 & - & $\operatorname{axSpA}$ \\
\hline Kong et al. & 2021 & China & 270 & 32 (IQR 26-40) & 22.5 (16-29) & - & 78.9 & - & AS \\
\hline Hur et al. & 2021 & South Korea & 1012 & - & - & - & 75.8 & - & $\mathrm{AS}$ \\
\hline Sorensen et al. & 2014 & Denmark & 1335 & 40.8 (SD 12.4) & - & - & 70.9 & - & AS \\
\hline
\end{tabular}

delay based on disease definition, there was little variation in the range of delay reported for the different definitions (axSpA: 2-8 years vs. AS: 0.67-7.5 years) (Supplementary Table 2). Where mean delay data had also been reported alongside median data, each article consistently reported a greater mean delay. Across these 15 studies, the reporting of delay using mean data resulted in an average delay being 2.7 years longer than when median data was used (Supplementary Table 3 ).

\section{Extent of diagnostic delay over time}

Four studies reported the change in diagnostic delay over time. Salvadorini et al. (2012) presented median delays over six decades from the 1950s through to 2000, showing a reduction in delay, with this halving every decade, apart from the 1970s to 1980s [30]. Calin et al. (1988) presented median delay over 15 time periods from the UK and also compared male delay with female delay over the same period
[39]. This study found a reduction in delay throughout the 20th century, although not to the extent found by Salvadorini et al.; overall median diagnostic delay in the UK in the middle of the 20th century was far shorter than in Italy. Reed et al.'s Australian study (2008) presented mean diagnostic delay over three decades, from 1978 to 1993, which showed diagnostic delay reducing from 13.8 years in 1978 to 4.3 years in 1993 [40]. Finally, a US study by Wright et al. (2015) examined the extent of a diagnostic delay from 1980 through to 2009. Though a reduction in delay was found, this was minimal, with delay from 1980 to 1999 being 6.2 years, and between 2000 and 2009 being 5.6 years [41].

\section{Factors association with diagnostic delay}

Forty-five studies $[5,8,10,14-19,21,23,24,27,32,34$, 42-71] examined the role of at least one specific factor for a possible association with diagnostic delay. In total, these studies reported 47 distinct factors, which were separated 
Table 2 Extent of median delay in diagnosis of axSpA $(n=25)$

\begin{tabular}{|c|c|c|c|c|c|c|c|}
\hline Author & Year & Country & Sample size & Disease definition & $\begin{array}{l}\text { Diagnostic } \\
\text { delay(years) }\end{array}$ & IQR & Range \\
\hline Seo et al. & 2014 & South Korea & 94 & axSpA & 8 & $3-15$ & \\
\hline Forejtova et al. & 2008 & Czech Republic & 979 & AS & 7.5 & $3.5-12.5$ & \\
\hline Bakland et al. & 2011 & Norway & 677 & AS & 7 & & \\
\hline Fallahi et al. & 2016 & Iran & 163 & AS & 6 & & $0-32$ \\
\hline Hamilton et al. & 2011 & UK & 807 & AS & 6 & $2-12$ & \\
\hline Merino et al. & 2021 & Spain & 469 & AS & 6 & $2-12$ & \\
\hline Aggarwal et al. & 2009 & India & 70 & AS & 5.9 & $3-11$ & \\
\hline Brandt et al. & 2007 & Germany & 350 & axSpA & 5 & & $0.1-45$ \\
\hline Sykes et al. & 2015 & UK & 1193 & axSpA & 5 & $2-12$ & \\
\hline Gerdan et al. & 2012 & Turkey & 393 & AS & 5 & 11 & \\
\hline Limsakul et al. & 2021 & Thailand & 177 & axSpA & 5 & $1.7-11.1$ & \\
\hline Garrido-Cumbrera et al. & 2019 & Europe & 2846 & axSpA & 4 & & \\
\hline Zengin et al. & 2021 & Turkey & 308 & axSpA & 4 & $3-5.5$ & \\
\hline Ozgocmen et al. & 2009 & Turkey & 279 & AS & 3 & & \\
\hline Omair et al. & 2017 & Saudi Arabia & 134 & axSpA & 3 & $1-6$ & \\
\hline Redeker et al. & 2019 & Germany & 4471 & axSpA & 2.3 & & $0.1-7.2$ \\
\hline Li et al. & 2019 & China & 208 & axSpA & 2.1 & & $4-74.8$ \\
\hline Salvadorini et al. & 2012 & Italy & 135 & AS & 2.1 & & $2-3$ \\
\hline Bodur et al. & 2010 & Turkey & 1381 & AS & 2 & & \\
\hline Masson Behar et al. & 2016 & France & 432 & axSpA & 2 & $1-7$ & \\
\hline Qian et al. & 2017 & China & 1251 & AS & 2 & $0-2$ & \\
\hline Reddy et al. & 2020 & India & 100 & axSpA & 2 & $0.5-5$ & \\
\hline Kong et al. & 2021 & China & 270 & AS & 2 & $0-5$ & \\
\hline Hur et al. & 2021 & South Korea & 1012 & AS & 1 & $0.25-4$ & \\
\hline Sorensen et al. & 2014 & Denmark & 1335 & AS & 0.67 & & \\
\hline
\end{tabular}

into 16 categories (Supplementary Tables 4 and 5). The majority of these were only investigated once in a single study, but seven factors had been statistically compared in more than five separate studies. These factors included gender (20 studies comparing delay between men and women $[5,8,14,17-19,23,24,42-52])$, HLAB27 negativity vs positivity (15 studies $[8,17-19,23$, $32,34,42,44,45,49,59,60,65,71])$, radiographic- vs. non-radiographic-axSpA (9 studies [19, 21, 49, 54-56, $67,68,72]$ ), juvenile vs adult disease-onset (7 studies [8, $14,16,18,19,23,49])$, family history of axSpA (5 studies $[8,19,23,42,45])$, presence at onset of uveitis or not (5 studies [5, 8, 19, 44, 45]) and presence of peripheral arthritis or not (5 studies [5, 8, 23, 45, 49]). Of these factors, gender and family history of axSpA had sufficient data concordance to determine that they had no influence on the extent of diagnostic delay experienced across the majority of studies. The study findings for the remaining factors reported contradictory directions of effect, preventing the determination of any definite association (or lack thereof) (Table 3).
Of the 20 studies which examined the difference in the extent of diagnostic delay experienced between men and women, 18 had undertaken a statistical comparison, of which only three found a significant difference in the delay of receiving a diagnosis between the sexes. With one exception [48], all of these studies had a greater proportion of men in their sample, ranging from 52.3 to $92.7 \%$. The majority of samples (88.9\%) were recruited from secondary care health settings, the exceptions being two studies, one using the general population [43] and another using patients from a defence medical rehabilitation centre [47]. Just under two-thirds (60.0\%) of articles defined disease as AS rather than axSpA (Table 4).

Five articles had assessed the role that patients' family history of axSpA has on the extent of diagnostic delay experienced. All articles used samples from secondary care, were predominantly male (ranging from 67.4 to $84.3 \%$ ) and found no association between the delay experienced in receiving a delayed diagnosis and whether patients did, or did not, have a family history of the same condition. Three out of five studies defined their disease of interest as AS rather than axSpA (Table 4). 
Table 3 Summary of factors and their association on diagnostic delay in axSpA

\begin{tabular}{|c|c|c|c|c|c|}
\hline & Characteristics & $\begin{array}{l}\text { Total no of studies } \\
\text { comparing factor }\end{array}$ & $\begin{array}{l}\text { Decreased } \\
\text { delay }\end{array}$ & No difference & $\begin{array}{l}\text { Increased } \\
\text { delay }\end{array}$ \\
\hline \multirow[t]{2}{*}{ Directional impact on delay } & Gender (male) & 18 & 1 & 15 & 2 \\
\hline & Family history of axSpA (yes) & 5 & 0 & 5 & 0 \\
\hline \multirow[t]{5}{*}{ Mixed impact on delay } & HLA-B27 (+) & 15 & 7 & 6 & 2 \\
\hline & Radiographic axSpA (yes) & 9 & 0 & 5 & 4 \\
\hline & Age of onset (<16 years) & 5 & 0 & 3 & 2 \\
\hline & Peripheral arthritis (yes) & 5 & 1 & 3 & 1 \\
\hline & Uveitis (yes) & 5 & 1 & 3 & 1 \\
\hline
\end{tabular}

Table 4 Articles comparing diagnostic delay between (i) males and females $(n=20)$ and (ii) patients with or without a family history of AS/ $\operatorname{axSpA}(n=5)$

\begin{tabular}{|c|c|c|c|c|c|c|c|c|c|c|c|}
\hline \multirow[t]{3}{*}{ Author } & \multirow[t]{3}{*}{ Year } & \multirow[t]{3}{*}{ Country } & \multirow[t]{3}{*}{ Sample size } & \multirow[t]{3}{*}{ Disease definition } & \multirow[t]{3}{*}{ Male $(\%)$} & \multicolumn{6}{|c|}{ Extent of diagnostic delay (years) } \\
\hline & & & & & & \multicolumn{3}{|c|}{ By gender } & \multicolumn{3}{|c|}{ By family history } \\
\hline & & & & & & Males & Female & $P$-values & Yes & No & $P$-values \\
\hline Bandinelli et al. & 2016 & Italy & 135 & $\operatorname{axSpA}$ & 67.4 & 9.91 & 6.3 & 0.0023 & 9.48 & 8.68 & 0.55 \\
\hline Geirsson et al. & 2010 & Iceland & 223 & AS & 65 & 8.3 & 9.6 & 0.87 & - & - & - \\
\hline Nakashima et al. & 2015 & Japan & 72 & AS & 83 & 6.9 & 5.5 & 0.47 & - & - & - \\
\hline Ma et al. & 2012 & South China & 70 & AS & 72.9 & 6.6 & 6.2 & $\mathrm{~N} / \mathrm{S}$ & - & - & - \\
\hline Aggarwal et al. & 2009 & India & 70 & AS & 84.3 & 6.5 & 8.6 & 0.23 & 7.1 & 6.6 & 0.68 \\
\hline Fallahi et al.* & 2016 & Iran & 163 & AS & 79 & 6 & 6.5 & 0.68 & 6.5 & 6 & 0.32 \\
\hline Hajialilo et al. & 2014 & Iran & 60 & AS & 88.3 & 5.9 & 8 & 0.14 & 6.5 & 6 & 0.64 \\
\hline Slobodin et al. & 2010 & Israel & 151 & axSpA & 52.3 & 5.9 & 5.7 & 0.87 & - & - & - \\
\hline Roussou et al. & 2010 & UK & 516 & axSpA & 33.3 & 5.56 & 6.27 & $\mathrm{~N} / \mathrm{S}$ & - & - & - \\
\hline Jones et al. & 2014 & UK & 138 & axSpA & - & 5.56 & 8.5 & - & - & - & - \\
\hline Dincer et al. & 2007 & Turkey & 111 & AS & 92.7 & 5.32 & 14.42 & 0.061 & - & - & - \\
\hline Sykes et al.* & 2015 & UK & 1193 & axSpA & - & 5 & 6 & $\mathrm{~N} / \mathrm{S}$ & - & - & - \\
\hline Coughlan et al. & 1981 & Ireland & 78 & AS & 73 & 4.6 & 5 & - & - & - & - \\
\hline Ibn Yacoub et al. & 2012 & Morocco & 130 & AS & 66.9 & 4.6 & 4.8 & 0.075 & - & - & - \\
\hline Ma et al. & 2012 & North China & 80 & AS & 78.6 & 4 & 4.1 & $\mathrm{~N} / \mathrm{S}$ & - & - & - \\
\hline Zengin et al.* & 2021 & Turkey & 308 & axSpA & 58.8 & 4 & 4 & 0.238 & - & - & - \\
\hline $\mathrm{Li}$ et al.* & 2019 & China & 208 & $\operatorname{axSpA}$ & 71.6 & 2.92 & 1.04 & 0.014 & 1.36 & 2.38 & $\mathrm{~N} / \mathrm{S}$ \\
\hline Bodur et al.* & 2012 & Turkey & 1381 & AS & 75.2 & 2 & 2.3 & 0.385 & - & - & - \\
\hline Qian et al.* & 2017 & China & 1251 & AS & 73 & 2 & 2 & $\mathrm{~N} / \mathrm{S}$ & - & - & - \\
\hline Reddy et al.* & 2020 & India & 100 & axSpA & 68 & 1 & 4 & 0.021 & - & - & - \\
\hline
\end{tabular}

*Diagnostic delay reported as median

$P$-values in bold indicates statistical significance. Dash (-) indicates no test for significance performed

$A S$, ankylosing spondylitis; $A x S p A$, axial spondyloarthritis; $U K$, United Kingdom; N/S, non-significant

\section{Quality assessment}

Of the 59 included studies, 28 had samples considered truly representative of the population of patients with axSpA, while 29 were somewhat representative of the population. Two had samples from a selected group. Ascertainment of exposure, i.e., proof of diagnosis, was made using secure records in 43 studies (the highest standard of quality for this item), while 11 were ascertained using structured interviews. Written self-report was used in three studies, and two did not describe how they ascertained patients' diagnosis. Assessment of outcome, i.e., assessment of diagnostic delay, did not reach the highest standard (independent blind assessment) in any study. Record linkage was used in 23 studies, and a further 28 used patient self-report. Eight did not describe how the diagnostic delay was confirmed. 
Ascertainment of exposure was the criteria most commonly fulfilled to the highest criteria $(n=43)$.

\section{Discussion}

This systematic review collated all available studies examining the extent of diagnostic delay in patients with axSpA, prioritising those reporting median data. Across all countries, patients with axSpA are experiencing years of diagnostic delay, the majority between 2 and 6 years, though delay appears to have reduced somewhat over the second half of the 20th century. Our findings also highlight the extent to which diagnostic delay based on mean data, rather than median, influences the interpretation of delay, with such studies consistently reporting longer periods of delay. We also found that many disease-, patient- or healthcarerelated factors had been considered in relation to their role on the extent of diagnostic delay experienced by patients with axSpA, but that few of these factors were examined across multiple studies, making it difficult to evaluate their part in delay. Where the role of a factor had been sufficiently examined, many articles reported contradictory directions of effect. However, 'family history of axSpA' and 'gender' were more concordant, showing no significant role in the extent of diagnostic delay experienced by patients.

\section{Extent of diagnostic delay}

It is evident that a patient with axSpA will most likely be delayed in receiving their diagnosis from between 2 and 6 years. Across this collection of studies, we were unable to identify any variables which influenced the length of delay reported, and this 4-year range could relate to the inclusion of studies with different sample sizes and health care settings. Even within the same country, delay ranged across several years, as exemplified by multiple studies from the UK (5-6 years), Turkey (2-5 years) and Germany (2.3-5 years). However, despite this, the range of 2-6 years does provide the axSpA community with a clearer benchmark of the current problem of delay across the globe. Our proposal that this range is 'typical' is further strengthened by the included article by Garrido-Cumbrera et al. [35]. Their large study of diagnostic delay across 13 European countries found a median delay of 4 years, falling midway within our own range. Furthermore, and somewhat encouragingly, a third $(n=8)$ of all articles reported a median delay of 2-2.3 years. Our findings were not influenced by the use of the different disease terms of 'AS' and 'axSpA', despite the fact that 'AS' would generally have been used before the 'axSpA' classification criteria was adopted.

Though the recent review by Zhao et al. contained twelve of the same articles identified within our assessment of median data $[5,8,9,15,16,23,26-29,31,35]$, their focus on mean data makes direct comparisons with our work difficult. We would suggest that our findings represent a more accurate indication of the 'usual' patient journey from symptom onset to final diagnosis due to the use of median data. The pooled diagnostic delay of 6.7 years (95\% CI 6.2-7.2) found by Zhao et al. exceeds the average reported by the majority of studies our review identified. Furthermore, where both measures of central tendency had been reported in the same study, this 'overestimation' of mean delay was consistently demonstrated. Finally, the argument for the use of median, over mean diagnostic delay data in patients with axSpA has been made previously by Sykes et al. (2015). Their study showed a median delay of 5.0 years, compared to a mean delay of the same sample of 8.5 years in a UK population [5]. Furthermore, they found that a third of patients experienced less than two years delay, and over a half experienced less than five years delay, results consistent with our own.

The results presented by our review provide a new, more accurate benchmark for general and country-specific diagnostic delay against which to measure success regarding the speed of diagnosis. Such benchmarks need to be as accurate and representative of the greatest number of patients as possible. Any concern about the loss of representation of the extremes of diagnostic delay can be allayed through presenting ranges associated with delay medians. It is therefore important that, when discussing diagnostic delay in axSpA, medians are the prioritised result. Such information from our review is needed as a starting point, so that the medical community can work towards the concept of a limited window of opportunity to achieve a swift diagnosis, prompt treatment and management provision for patients, as now achieved in rheumatoid arthritis [73].

\section{Role of specific factors on diagnostic delay experience}

This review was able to consider how diagnostic delay for axSpA has changed over time. Despite the limited number of articles examining this concept, since the mid-20th century, it appears that diagnostic delay has been reducing. Reasons for this may be related to increased disease awareness [30], advances in diagnostic technology, such as magnetic resonance imaging [74] and improved aetiological understanding [75]. However, in recent decades, there are some suggestions that the rate of reduction of delay may be plateauing, implying further policy and methodological change is required to continue reduction to delay.

Of all the factors which have previously been examined in relation to their role on delay, only 'gender' and 'family history of axSpA' were studied to a sufficient extent and reported enough concordant findings to be able to draw 
conclusions on their role upon delay. The predominance of non-significant findings across the vast majority of these studies suggests that neither factors have a role in the delay experienced by patients with axSpA. The historical misconception of axSpA as a 'male disease' would suggest that delay should be greater in females. However, this has not been translated into the findings from the studies which have specifically compared the diagnostic delay between men and women. This could relate to sample selection issues, but the high frequency of studies found would suggest this is a consistent event.

Five studies examined the relationship between family history of axSpA and diagnostic delay, of which none found a significant association. In contrast, having a family member with axSpA has previously been shown to be a risk factor for developing axSpA. Lunteran et al. reported $15 \%$ of patients suspected of axSpA having a family history of the disease, and a strong association between a patient having first-degree relatives with AS and being positive for HLA-B27 (OR 7.8 (95\% CI 3.8-16.0) [76]. Ez-Zaitouni et al. also found a positive association between family history and ASAS criteria in two cohorts (OR 3.3 (95\% CI 2.0-5.3); OR 2.1 (1.3-3.3), respectively) [77]. It is therefore plausible that a family history of axSpA is a factor which would reduce diagnostic delay in patients presenting with axSpA-like symptoms, potentially due to patients' increased knowledge of the condition or healthcare professionals being aware of an increased risk of axSpA development in individuals with a spondyloarthritis family history. However, the fact that patients with a family history of axSpA appear to experience no difference in delay than patients with no family history of the disease could be the result of several factors. The disparate symptom profiles may not register with the already diagnosed family member, and lack of contact or an unwillingness for individuals to share health problems with family members may also be factors. Though Ez-Zaitouni et al. found family history to be associated with ASAS criteria for $\operatorname{axSpA}$, it was not associated with sacroiliitis [77]. The implication here could be that patients' symptoms, while diagnostically suggestive, might not be similar enough to their relatives' symptoms for them to raise in consultation with their healthcare professional. It could also be that in primary care, the question of family history does not arise early on and only arises after the healthcare professional being consulted had become suspicious of the disease. All these issues suggest education and discussion of health (particularly hereditary) conditions should be promoted in patients with axSpA.

\section{Strengths and limitations}

The main strength of this systematic review is that it is the first to synthesise the median delay data to provide a global benchmark range, presenting more robust delay values across individual countries, and providing the most accurate understanding of diagnostic delay for axial spondyloarthritis to date. This is reinforced by the direct comparison of means to medians in studies where they are calculated from the same sample. Additionally, this systematic review details and compares many disease-, patient- and healthcarerelated factors which are associated with diagnostic delay, which suggests several avenues for future research. The main limitation of this systematic review is the high level of variability, even within the same countries, which is apparent across the included studies.

\section{Conclusion}

This systematic review has highlighted that, despite marked improvements over the last few decades, the delay experienced by patients in receiving a diagnosis of axial spondyloarthritis remains unacceptably long across many counties. However, our focus on median data does provide a more robust indicator of the extent of this delay for the majority of patients and can therefore act as a new benchmark for future research. Regarding the role of disease and patient-related factors, gender and family history do not appear to influence diagnostic delay, but while studies examining other factors were numerous, evidence of associations between patient characteristics and diagnostic delay remain contradictory or limited. Healthcare systems must continue to strive to reduce the delay experienced by patients, and further rigorous research examining which patient groups are most vulnerable to experiencing delay is needed.

Supplementary Information The online version contains supplementary material available at https://doi.org/10.1007/s10067-022-06100-7.

Acknowledgements We would like to thank the systematic review team from the School of Medicine, Keele University, for their support

Author contribution All authors have made a substantial contribution to conducting this work, the drafting and writing of this manuscript, and all provide final approval for this version to be published and agree to be accountable for all aspects of the work. Individual contributions are as follows: Study concept and design: CAH, JP, SR, CDM and JAP. Data collection and interpretation: CAH, JP, AC and JAP. Analysis: CAH and JAP. Manuscript preparation: CAH, JP, SR, CDM, AC and JAP. Final approval of manuscript: CAH, JP, SR, CDM, AC and JAP.

Funding CAH is funded by an NIHR School for Primary Care Research PhD Studentship. CDM is funded by the NIHR Applied Research Collaboration West Midlands and the NIHR SPCR. JP is funded by an NIHR West Midlands Accelerated Scholar Fellowship. The study sponsors had no role in study design; in the collection, analysis and interpretation of data; in the writing of the report; and in the decision to submit the paper for publication. This paper presents independent research which is part-funded by the NIHR ARC West Midlands. The views expressed are those of the author(s) and do not 
necessarily reflect those of the NHS, the NIHR (UK) or the Department of Health and Social Care.

\section{Declarations}

Conflict of interest Keele School of Medicine have received funding from BMS to support a non-pharmacological atrial fibrillation trial. The individual authors have no conflicts of interest.

Open Access This article is licensed under a Creative Commons Attribution 4.0 International License, which permits use, sharing, adaptation, distribution and reproduction in any medium or format, as long as you give appropriate credit to the original author(s) and the source, provide a link to the Creative Commons licence, and indicate if changes were made. The images or other third party material in this article are included in the article's Creative Commons licence, unless indicated otherwise in a credit line to the material. If material is not included in the article's Creative Commons licence and your intended use is not permitted by statutory regulation or exceeds the permitted use, you will need to obtain permission directly from the copyright holder. To view a copy of this licence, visit http://creativecommons.org/licenses/by/4.0/.

\section{References}

1. Kameda H, Kobayashi S, Tamura N, Kadono Y, Tada K, Yamamura M, Tomita T (2021) Non-radiographic axial spondyloarthritis. Modern Rheumatology 31:277-282

2. Morgan CLI, White A, Tomlinson M, Scott A, Tian H (2020) O16 Incidence, prevalence and associated comorbidity of axSpA within the UK: a retrospective database analysis. Rheumatology 59

3. Lapane KL, Khan S, Shridharmurthy D, Beccia A, Dubé C, Yi E, Kay J, Liu S-H (2020) Primary care physician perspectives on barriers to diagnosing axial spondyloarthritis: a qualitative study. BMC Family Practice 21:204

4. Hamilton L, Macgregor A, Toms A, Warmington V, Pinch E, Gaffney K (2015) The prevalence of axial spondyloarthritis in the UK: a cross-sectional cohort study. BMC Musculoskelet Disord 16:392

5. Sykes MP, Doll H, Sengupta R, Gaffney K (2015) Delay to diagnosis in axial spondyloarthritis: are we improving in the UK? Rheumatology (Oxford) 54:2283-2284

6. Doward LC, Spoorenberg A, Cook SA, Whalley D, Helliwell PS, Kay LJ, McKenna SP, Tennant A, van der Heijde D, Chamberlain MA (2003) Development of the ASQoL: a quality of life instrument specific to ankylosing spondylitis. Ann Rheum Dis 62:20-26

7. Yi E, Ahuja A, Rajput T, George AT, Park Y (2020) Clinical, economic, and humanistic burden associated with delayed diagnosis of axial spondyloarthritis: a systematic review. Rheumatol Ther $7: 65-87$

8. Fallahi S, Jamshidi AR (2016) Diagnostic delay in ankylosing spondylitis: related factors and prognostic outcomes. Arch Rheumatol 31:24-30

9. Seo MR, Baek HL, Yoon HH, Ryu HJ, Choi HJ, Baek HJ, Ko KP (2015) Delayed diagnosis is linked to worse outcomes and unfavourable treatment responses in patients with axial spondyloarthritis. Clin Rheumatol 34:1397-1405

10. Cakar E, Taskaynatan MA, Dincer U, Kiralp MZ, Durmus O, Ozgül A (2009) Work disability in ankylosing spondylitis: differences among working and work-disabled patients. Clin Rheumatol 28:1309-1314
11. Gunasekera W, Shaddick G, Jobling A, Smith A, Sengupta R (2014) AB0735 Diagnostic delay worsens mobility and work disability in ankylosing spondylitis. Annals Rheumatic Diseases 73:1046-1046

12. Zhao SS, Pittam B, Harrison NL, Ahmed AE, Goodson NJ, Hughes DM (2021) Diagnostic delay in axial spondyloarthritis: a systematic review and meta-analysis. Rheumatology (Oxford) 60:1620-1628

13. Wells GA, Shea B, O'Connell D, Peterson J, Welch V, Losos M (n.d.) The Newcastle-Ottawa Scale (NOS) for assessing the quality of nonrandomised studies in meta-analyses. http://www.ohri.ca/ programs/clinical_epidemiology/oxford.asp

14. Bodur H, Ataman S, Buğdaycı DS et al (2012) Description of the registry of patients with ankylosing spondylitis in Turkey: TRASD-IP. Rheumatol Int 32:169-176

15. Gerdan V, Akar S, Solmaz D et al (2012) Initial diagnosis of lumbar disc herniation is associated with a delay in diagnosis of ankylosing spondylitis. J Rheumatol 39:1996-1999

16. Ozgocmen S, Ardicoglu O, Kamanli A et al (2009) Pattern of disease onset, diagnostic delay, and clinical features in juvenile onset and adult onset ankylosing spondylitis. J Rheumatol 36:2830-2833

17. Zengin OEN, Türkbeyler IH (2021) Evaluation of clinical features, prognostic factors, and treatment responses of patients with axial spondyloarthritis in southeastern Anatolia. J Harran Univ Med Faculty 18:12-17

18. Qian Q, Xu X, He H et al (2017) Clinical patterns and characteristics of ankylosing spondylitis in China. Clin Rheumatol 36:1561-1568

19. Li J, Xu Y, Chen Y, Ye C, Huang J, Qian L, Xin W, Li T, Ye S (2019) A multidisciplinary clinic approach to improve physicianrelated diagnostic delay for patients with axial spondyloarthritis: a retrospective study. J Int Med Res 47:2483-2491

20. Kong W, Jefferies C, Learch TJ et al (2022) Risk factors for spinal structural damage in a Chinese cohort with ankylosing spondylitis. J Clin Rheumatol 28:e118-e124

21. Brandt HC, Spiller I, Song IH, Vahldiek JL, Rudwaleit M, Sieper J (2007) Performance of referral recommendations in patients with chronic back pain and suspected axial spondyloarthritis. Ann Rheum Dis 66:1479-1484

22. Redeker I, Callhoff J, Hoffmann F, Haibel H, Sieper J, Zink A, Poddubnyy D (2019) Determinants of diagnostic delay in axial spondyloarthritis: an analysis based on linked claims and patientreported survey data. Rheumatology (Oxford) 58:1634-1638

23. Aggarwal R, Malaviya AN (2009) Diagnosis delay in patients with ankylosing spondylitis: factors and outcomes - an Indian perspective. Clin Rheumatol 28:327-331

24. Reddy K, Raut A, Patil P (2020) Axial spondyloarthritis in India: determining the delay in diagnosis, impact on work productivity, and attitude of patients toward treatment. Indian J Rheumatol $15: 267-274$

25. Hur JW, Ko KM, Park KS, Hong SJ, Kim HS, Lee MS (2021) Real-world experiences of the diagnosis process in Korean patients with ankylosing spondylitis based on a self-report questionnaire. J Int Med Res 49:3000605211004201

26. Hamilton L, Gilbert A, Skerrett J, Dickinson S, Gaffney K (2011) Services for people with ankylosing spondylitis in the UK - a survey of rheumatologists and patients. Rheumatology (Oxford) 50:1991-1998

27. Forejtová S, Mann H, Stolfa J, Vedral K, Fenclová I, Némethová D, Pavelka K (2008) Factors influencing health status and disability of patients with ankylosing spondylitis in the Czech Republic. Clin Rheumatol 27:1005-1013

28. Sørensen J, Hetland ML (2015) Diagnostic delay in patients with rheumatoid arthritis, psoriatic arthritis and ankylosing spondylitis: 
results from the Danish nationwide DANBIO registry. Ann Rheum Dis 74:e12

29. Masson Behar V, Dougados M, Etcheto A et al (2017) Diagnostic delay in axial spondyloarthritis: a cross-sectional study of 432 patients. Joint Bone Spine 84:467-471

30. Salvadorini G, Bandinelli F, Delle Sedie A, Riente L, Candelieri A, Generini S, Possemato N, Bombardieri S, Matucci-Cerinic M (2012) Ankylosing spondylitis: how diagnostic and therapeutic delay have changed over the last six decades. Clin Exp Rheumatol 30:561-565

31. Bakland G, Gran JT, Nossent JC (2011) Increased mortality in ankylosing spondylitis is related to disease activity. Ann Rheum Dis 70:1921-1925

32. Omair MA, AlDuraibi FK, Bedaiwi MK et al (2017) Prevalence of HLA-B27 in the general population and in patients with axial spondyloarthritis in Saudi Arabia. Clin Rheumatol 36:1537-1543

33. Merino M, Braçe O, González-Domínguez A, Hidalgo-Vega Á, Garrido-Cumbrera M, Gratacós J (2021) Social economic costs of ankylosing spondylitis in Spain. Clin Exp Rheumatol 39:357-364

34. Limsakul N, Chiowchanwisawakit P, Permpikul P, Thanaketpaisarn Y (2021) Younger age of onset and uveitis associated with HLA-B27 and delayed diagnosis in Thai patients with axial spondyloarthritis. Sci Rep 11:13536

35. Garrido-Cumbrera M, Poddubnyy D, Gossec L et al (2019) The European map of axial spondyloarthritis: capturing the patient perspective - an analysis of 2846 patients across 13 countries. Curr Rheumatol Rep 21:19

36. van der Linden S, Valkenburg HA, Cats A (1984) Evaluation of diagnostic criteria for ankylosing spondylitis. A proposal for modification of the New York criteria. Arthritis Rheum 27:361-368

37. Rudwaleit M, van der Heijde D, Landewé R et al (2009) The development of Assessment of SpondyloArthritis International Society classification criteria for axial spondyloarthritis (part II): validation and final selection. Ann Rheum Dis 68:777-783

38. Rudwaleit M, Landewé R, van der Heijde D et al (2009) The development of Assessment of SpondyloArthritis International Society classification criteria for axial spondyloarthritis (part I): classification of paper patients by expert opinion including uncertainty appraisal. Ann Rheum Dis 68:770-776

39. Calin A, Elswood J, Rigg S, Skevington SM (1988) Ankylosing spondylitis - an analytical review of 1500 patients: the changing pattern of disease. J Rheumatol 15:1234-1238

40. Reed MD, Dharmage S, Boers A, Martin BJ, Buchanan RR, Schachna L (2008) Ankylosing spondylitis: an Australian experience. Intern Med J 38:321-327

41. Wright KA, Crowson CS, Michet CJ, Matteson EL (2015) Time trends in incidence, clinical features, and cardiovascular disease in ankylosing spondylitis over three decades: a population-based study. Arthritis Care Res (Hoboken) 67:836-841

42. Bandinelli F, Salvadorini G, Delle Sedie A, Riente L, Bombardieri S, Matucci-Cerinic M (2016) Impact of gender, work, and clinical presentation on diagnostic delay in Italian patients with primary ankylosing spondylitis. Clin Rheumatol 35:473-478

43. Geirsson AJ, Eyjolfsdottir H, Bjornsdottir G, Kristjansson K, Gudbjornsson B (2010) Prevalence and clinical characteristics of ankylosing spondylitis in Iceland - a nationwide study. Clin Exp Rheumatol 28:333-340

44. Nakashima Y, Ohishi M, Okazaki K, Fukushi J, Oyamada A, Hara D, Doi T, Akasaki Y, Yamada H, Iwamoto Y (2016) Delayed diagnosis of ankylosing spondylitis in a Japanese population. Mod Rheumatol 26:421-425

45. Hajialilo M, Ghorbanihaghjo A, Khabbazi A, Kolahi S, Rashtchizadeh N (2014) Ankylosing spondylitis in Iran; late diagnosis and its causes. Iran Red Crescent Med J 16:e11798
46. Slobodin G, Reyhan I, Avshovich N et al (2011) Recently diagnosed axial spondyloarthritis: gender differences and factors related to delay in diagnosis. Clin Rheumatol 30:1075-1080

47. Jones A, Harrison N, Jones T, Rees JD, Bennett AN (2014) Time to diagnosis of axial spondylarthritis in clinical practice: signs of improving awareness? Rheumatology (Oxford) 53:2126-2127

48. Roussou E, Sultana S (2011) Spondyloarthritis in women: differences in disease onset, clinical presentation, and Bath Ankylosing Spondylitis Disease Activity and Functional indices (BASDAI and BASFI) between men and women with spondyloarthritides. Clin Rheumatol 30:121-127

49. Dincer U, Cakar E, Kiralp MZ, Dursun H (2008) Diagnosis delay in patients with ankylosing spondylitis: possible reasons and proposals for new diagnostic criteria. Clin Rheumatol 27:457-462

50. Ibn Yacoub Y, Amine B, Laatiris A, Hajjaj-Hassouni N (2012) Gender and disease features in Moroccan patients with ankylosing spondylitis. Clin Rheumatol 31:293-297

51. Coughlan RJ, Molony J, Bresnihan B (1981) Ankylosing spondylitis: a two-year experience. Ir Med J 74:190-191

52. Ma HJ, Yin QF, Hu FP, Guo MH, Liu XD, Liu Y, Xu QY (2012) Different clinical features in patients with ankylosing spondylitis from southern and northern China. Int J Rheum Dis 15:154-162

53. Quraishi MK, Badsha H, Khan B, Shahzeb M, Hegde S, Mofti A, Ooi KK (2018) Interethnic variations and clinical features of spondyloarthropathies in a Middle Eastern Country. Open Rheumatol J 12:10-18

54. Kidd BL, Cawley MI (1988) Delay in diagnosis of spondarthritis. Br J Rheumatol 27:230-232

55. Burgos-Varga R, Wei JC, Rahman MU et al (2016) The prevalence and clinical characteristics of nonradiographic axial spondyloarthritis among patients with inflammatory back pain in rheumatology practices: a multinational, multicenter study. Arthritis Res Ther 18:132

56. Gavali M, Konda K, Rajasekhar L, Devarasetti PK, Irlapati RV (2015) A comparison of clinical and laboratory profile of nonradiographic axial spondyloarthritis and ankylosing spondylitis. Indian J Rheumatol 10:129-132

57. Chimenti MS, Conigliaro P, Navarini L et al (2020) Demographic and clinical differences between ankylosing spondylitis and nonradiographic axial spondyloarthritis: results from a multicentre retrospective study in the Lazio region of Italy. Clin Exp Rheumatol 38:88-93

58. Zwolak R, Suszek D, Graca A, Mazurek M, Majdan M (2019) Reasons for diagnostic delays of axial spondyloarthritis. Wiad Lek 72:1607-1610

59. Feldtkeller E, Khan MA, van der Heijde D, van der Linden S, Braun J (2003) Age at disease onset and diagnosis delay in HLAB27 negative vs. positive patients with ankylosing spondylitis. Rheumatol Int 23:61-66

60. Chung HY, Machado P, van der Heijde D, D'Agostino MA, Dougados M (2011) HLA-B27 positive patients differ from HLA-B27 negative patients in clinical presentation and imaging: results from the DESIR cohort of patients with recent onset axial spondyloarthritis. Ann Rheum Dis 70:1930-1936

61. Sullivan C, Quinn K, Harney S, Ryan JG (2014) The use of antiTNF therapy for ankylosing spondylitis in everyday rheumatology practice and the relationship to disease activity, work disability and diagnostic delay. Ir J Med Sci 183:579-584

62. Abdul-Sattar A, Abou El Magd S (2017) Prevalence and associated risk factors for work disability in Egyptian patients with ankylosing spondylitis from one center. Int J Rheum Dis 20:2028-2034

63. Koko V, Ndrepepa A, Skënderaj S, Ploumis A, Backa T, Tafaj A (2014) An epidemiological study on ankylosing spondylitis in southern Albania. Mater Sociomed 26:26-29 
64. Zhao J, Zheng W, Zhang C, Li J, Liu D, Xu W (2015) Radiographic hip involvement in ankylosing spondylitis: factors associated with severe hip diseases. J Rheumatol 42:106-110

65. Bakland G, Nossent HC, Gran JT (2005) Incidence and prevalence of ankylosing spondylitis in Northern Norway. Arthritis Rheum 53:850-855

66. Nie A, Wang C, Song Y, Xie X, Yang H, Chen H (2018) Prevalence and factors associated with disturbed sleep in outpatients with ankylosing spondylitis. Clin Rheumatol 37:2161-2168

67. Kishimoto M, Ono K, Fukui S, et al. (2021) Clinical characteristics of non-radiographic versus radiographic axial spondyloarthritis in Asia and non-radiographic axial spondyloarthritis in other regions: results of the cross-sectional ASAS-COMOSPA study. RMD Open 7

68. Su J, Wang R, Duan X, et al. (2021) Clinical characteristics of axial spondyloarthritis patients in China: results from ChinaSpA, the Chinese Spondyloarthritis Registry. Clin Exp Rheumatol

69. Bedaiwi MK, Baeshen MO, Bin Zuair A, AlRasheed RF (2021) The delay of diagnosis in spondyloarthropathy patients in a tertiary hospital in Saudi Arabia. Cureus 13:e12629

70. Maatallah K, Ben Ammar L, Ferjani H, Kaffel D, Hamdi W (2022) Clinical, laboratory, and radiological characteristics of patients with late-onset spondylarthritis. The Egyptian Rheumatologist 44:19-23

71. Zhang S, Wang Y, Peng L et al (2020) Comparison of clinical features in HLA-B27 positive and negative patients with axial spondyloarthritis: results from a cohort of 4,131 patients. Front Med (Lausanne) 7:609562

72. Chimenti MS, Conigliaro P, Navarini L et al (2020) Demographic and clinical differences between ankylosing spondylitis and non-radiographic axial spondyloarthritis: results from a multicentre retrospective study in the Lazio region of Italy. Clin Exp Rheumatol 38:88-93

73. Cush JJ (2007) Early rheumatoid arthritis - is there a window of opportunity? J Rheumatol Suppl 80:1-7

74. Lukas C, Cyteval C, Dougados M, Weber U (2018) MRI for diagnosis of axial spondyloarthritis: major advance with critical limitations 'Not everything that glisters is gold (standard)'. RMD Open 4:e000586

75. Zhu W, He X, Cheng K, Zhang L, Chen D, Wang X, Qiu G, Cao X, Weng X (2019) Ankylosing spondylitis: etiology, pathogenesis, and treatments. Bone Research 7:22

76. van Lunteren M, Sepriano A, Landewé R, Sieper J, Rudwaleit M, van der Heijde D, van Gaalen F (2018) Do ethnicity, degree of family relationship, and the spondyloarthritis subtype in affected relatives influence the association between a positive family history for spondyloarthritis and HLA-B27 carriership? Results from the worldwide ASAS cohort. Arthritis Res Ther 20:166

77. Ez-Zaitouni Z, Hilkens A, Gossec L, Berg IJ, Landewé R, Ramonda R, Dougados M, van der Heijde D, van Gaalen F (2017) Is the current ASAS expert definition of a positive family history useful in identifying axial spondyloarthritis? Results from the SPACE and DESIR cohorts. Arthritis Res Ther 19:118

Publisher's note Springer Nature remains neutral with regard to jurisdictional claims in published maps and institutional affiliations. 